Federal Reserve Bank of Minneapolis

Research Department Staff Report 224

December 1996

\title{
Can the Mortensen-Pissarides Matching Model Match the Business Cycle Facts?*
}

\author{
Harold L. Cole \\ Federal Reserve Bank of Minneapolis \\ Richard Rogerson \\ Federal Reserve Bank of Minneapolis \\ and University of Minnesota
}

\begin{abstract}
We examine whether the Mortensen-Pissarides matching model can account for the business cycle facts on employment, job creation, and job destruction. A novel feature of our analysis is its emphasis on the reduced-form implications of the matching model. Our main finding is that the model can account for the business cycle facts, but only if the average duration of a nonemployment spell is relatively high —about nine months or longer.

*We thank Christopher Pissarides, Monika Merz, Ricardo Caballero, and Olivier Blanchard, as well as seminar participants at the NBER Summer Institute, the Federal Reserve Bank of Philadelphia, Rice University, Universidad Carlos III, Universitat Pompeu Fabra, Universidad de Alicante, Hong Kong University of Science and Technology, Chinese University of Hong Kong, University of Pennsylvania, and the Canadian Macroeconomic Study Group. The views expressed herein are those of the author(s) and not necessarily those of the Federal Reserve Bank of Minneapolis or the Federal Reserve System.
\end{abstract}




\section{Introduction}

A rapidly emerging literature on the aggregate labor market focuses on the flows of workers across establishments and through labor market states in order to better understand the behavior of aggregate employment and unemployment. ${ }^{1}$ A major motivation for this focus is the realization that many labor market policies are best understood through their impact on the underlying labor market flows. Obvious examples include dismissal costs and unemployment insurance. ${ }^{2}$ Recent advances in measuring the flows of workers across establishments are important factors assisting this modeling effort, thereby imposing more discipline on the model-building exercise. ${ }^{3}$

One structure that has been used extensively to study labor market flows is that of matching models. The Mortensen-Pissarides (1994) matching model is arguably the prototypical model from this class of matching models. They build a model in which idiosyncratic shocks to job matches create an incentive for match destruction and creation. This reallocation of employment across matches is mediated by a matching function, requires time and resources, and is stochastic from the individual's perspective. They show analytically that their model is qualitatively consistent with some of the empirical regularities that are displayed by job creation and job destruction over the business cycle.

In this paper, we examine in greater detail whether the Mortensen-Pissarides matching model can account for the business cycle facts on employment, job creation, and job destruction. Although matching models have been used rather extensively recently, there has been little systematic work to evaluate their quantitative properties with regard to labor market flows over the business cycle. ${ }^{4}$ One recent counterexample is offered by Merz (1996). She tries to account for the flow into and out of unemployment over the business cycle, rather than job creation and job destruction. A feature that distinguishes her analysis from that of

\footnotetext{
${ }^{1}$ Examples include Pissarides (1990), Mortensen and Pissarides (1994), Bertola and Ichino (1995), Greenwood, MacDonald and Zhang (1996), Merz (1996) and Caballero and Hammour (1996).

${ }^{2}$ Recent examples of policy evaluation include Bentolila and Bertola (1990), Hopenhayn and Rogerson (1993), Millard and Mortensen (1995), and Bertola and Rogerson (1997).

${ }^{3}$ Dunne, Roberts and Samuelson (1987), Davis and Haltiwanger (1992) and Blanchard and Diamond (1990) are examples of papers which document these flows.

${ }^{4}$ The reader familiar with the Mortensen-Pissarides article is aware that they report some success in matching business cycle facts for a simulated version of their model. As we show in Section 5, this success does not persist if one considers a larger set of facts.
} 
ours and Mortensen and Pissarides is her assumption that all (endogenous) separations are temporary rather than permanent.

A novel feature of our analysis is its emphasis on the equilibrium reduced-form implications of the Mortensen-Pissarides model. We argue that our representation of the equilibrium process implied by the structural model provides a convenient way to both assess the model's ability to account for the data and to uncover the role of various factors in generating specific results. For example, we show analytically that the speed with which employment responds following an aggregate shock is an important determinant of the model's ability to match the business cycle facts. An additional advantage of the reduced-form approach is that it is robust to several extensions and/or variations to the structural model.

The main finding of our analysis is that the reduced form implied by the MortensenPissarides model can account quite well for the business cycle facts. A key qualification, however, is that the extent to which the model matches the business cycle facts is very dependent upon the steady state about which the model fluctuates. In this regard, the average hazard rate for escape from unemployment to employment is a key parameter. We find that an escape rate on the order of one-third for a quarterly model is required. We argue that a hazard of this magnitude in a representative agent model is consistent with the data, if one considers individuals who are recorded as out of the labor force, but who want a job, to be (low intensity) searchers. This view is consistent with the assumptions Blanchard and Diamond $(1989,1990)$ use in their empirical analyses of labor market flows. This finding suggests that incorporating heterogeneity in worker search effort may be an important theoretical extension to the framework. Our finding is consistent with that of Caballero and Hammour (1996). They argue in a similar model that one way to obtain a negative correlation between job creation and job destruction is to diminish the importance of the unemployment stock as an incentive for entrepreneurs to create jobs. In our model, this is accomplished by having a high average value of unemployment, which is achieved by a low hazard rate.

The outline of the paper follows. In the next section, we document the business cycle facts for employment, job creation, and job destruction. In Section 3, we describe the Mortensen-Pissarides matching model and explain our reduced-form approach. Section 
4 develops some analytic results that help articulate key tradeoffs in matching the model with the data. Section 5 presents our quantitative results. Section 6 discusses the issue of calibrating steady-state values. Section 7 concludes.

\section{Business Cycle Facts For Employment, Job Creation, and Job Destruction}

In this section, we document the cyclical properties of employment, job creation, and job destruction. As is standard in business cycle studies, we use observations at the quar-

terly frequency. It is widely regarded that the highest quality data on job creation and job destruction is based on the LRD data first used by Davis and Haltiwanger (1992) and is documented recently in Davis, Haltiwanger, and Schuh (1996). This data only covers the manufacturing sector for the period 1972:2-1988:4. This dictates the scope and time frame of our empirical analysis. Our employment measure is the Citibase series for workers on manufacturing payrolls. Since job creation and job destruction series are based on employment information gathered in February, May, August, and November, we use employment figures for these same months.

We adopt the definitions for job creation and job destruction used in Davis, Haltiwanger, and Schuh (1996). Job creation in period $t\left(C_{t}\right)$ is the sum of all net employment gains at establishments experiencing positive net employment gains between $t-1$ and $t$. Job destruction in period $t\left(D_{t}\right)$ is the sum of all net employment losses at establishments experiencing negative net employment gains between $t-1$ and $t$. The employment measure on which these statistics are based is also workers on manufacturing payrolls. Literally, job creation measures net additions to payrolls at establishments experiencing increases in the size of their payrolls between two points in time.

The three series we study are linked by the identity

$$
E_{t}-E_{t-1}=C_{t}-D_{t}
$$

where $E_{t}$ is employment at period $t$. If, as in Davis, Haltiwanger, and Schuh (1996), the rates of job creation and job destruction, denoted by $C R_{t}$ and $D R_{t}$, respectively, are obtained by expressing the creation and job destruction measures as fractions relative to the mean of current and lagged employment, then dividing both sides of (1) by the mean of current and 
lagged employment produces an equivalent identity

$$
\frac{E_{t}-E_{t-1}}{.5\left(E_{t-1}+E_{t}\right)}=C R_{t}-D R_{t} .
$$

Equation (2) which basically says that the growth rate in employment between periods $t-1$ and $t$ is equal to the difference between the job creation rate and the job destruction rate. For reasons of symmetry, it seems preferable to either work with all series in levels or with all series in rates. Following most business cycle studies, we report results for the case using data in levels. ${ }^{5}$

We document the cyclical properties of these series following the standard practice in the business cycle literature. The cyclical component of a series is defined to be the deviations from a trend and is obtained by applying the Hodrick-Prescott filter to data which has been seasonally adjusted and logged. (See Cooley (1995) for details on this procedure.) In our quantitative work, we apply the same detrending procedure to the data that is generated by the model. As a practical matter, we found that our summary statistics are little affected by simply using the logged data in place of the deviations from the trend. Moreover, if we use the seasonally unadjusted data, the facts that are central to our analysis are essentially the same. While in this particular case the choice of procedure does not seem to matter that much, some choice must be made in order to present the business cycle facts, so we follow the common practice of basing our facts on data that is seasonally adjusted and filtered. ${ }^{6}$

Table 1 presents several summary statistics. Note that since each series is logged prior to detrending, deviations correspond to percent deviations.

\footnotetext{
${ }^{5}$ We repeated our analysis based on the series in growth rate form and found that it did not affect our conclusions.

${ }^{6}$ Seasonally unadjusted series for $C R_{t}$ and $D R_{t}$ were obtained from the Census. We construct series for $C_{t}$ and $D_{t}$ using the appropriate seasonally unadjusted manufacturing employment data from the establishment survey and then seasonally adjust the three series $\left(C_{t}, D_{t}\right.$, and $\left.E_{t}\right)$ using the Census X11 seasonal adjustment routine for quarterly data.
} 
Table 1

Summary Statistics 1972:2-1988:4

(data is seasonally adjusted and HP filtered)

\begin{tabular}{|c|c|c|}
\hline \multicolumn{3}{|c|}{ 1a. Standard Deviations and Autocorrelations } \\
\hline & standard deviation & autocorrelation \\
\hline Employment & .030 & .90 \\
\hline Job Creation & .117 & .51 \\
\hline Job Destruction & .197 & .65 \\
\hline
\end{tabular}

\begin{tabular}{|c|c|c|c|}
\hline \multicolumn{4}{|c|}{ 1b. Contemporaneous Correlations } \\
\hline & Employment & Job Creation & Job Destruction \\
\hline Employment & 1.00 & -.01 & -.23 \\
\hline Job Creation & -.01 & 1.00 & -.65 \\
\hline Job Destruction & -.23 & -.65 & 1.00 \\
\hline
\end{tabular}

\begin{tabular}{|c|c|c|c|c|c|c|c|}
\hline \multicolumn{1}{|c|}{ 1c. Correlations With Employment at Leads and Lags } \\
\hline & $t-3$ & $t-2$ & $t-1$ & $t$ & $t+1$ & $t+2$ & $t+3$ \\
\hline Job Creation at $t$ & -.41 & -.61 & -.63 & -.03 & .22 & .36 & .45 \\
\hline Job Destruction at $t$ & .13 & .43 & .58 & -.26 & -.52 & -.62 & -.63 \\
\hline
\end{tabular}

Rather than walking the reader through the previous tables, we close this section with a summary list of the facts that are used in the subsequent analysis: ${ }^{7}$

- Volatility: Job creation is roughly four times as volatile as employment, and job destruction is more than six times as volatile.

- Persistence: All three series display strong positive autocorrelation, but the autocorrelation for employment, which is .9 , is nearly twice that for the other two series.

- Contemporaneous Correlations: Job creation and job destruction have a fairly large negative correlation. Destruction is (weakly) negatively correlated with employment, whereas creation is virtually uncorrelated with employment.

\footnotetext{
${ }^{7}$ Using data for Michigan, Foote (1996) found that the standard deviation of the job creation rate exceeded that of the job destruction rate in some industries. He does not report the coefficient of variation, so it is not clear that this finding is necessarily counter to the one we report here. He also finds a negative correlation between job creation and job destruction.
} 
- Dynamics: Job creation is negatively correlated with lagged employment and positively correlated with future employment. The opposite pattern holds for job destruction.

\section{The Mortensen-Pissarides Matching Model}

In this section, we lay out the Mortensen-Pissarides (MP) matching model and examine the reduced-form process for employment, job creation, and job destruction implied by the model's equilibrium. We proceed in two steps. First, we motivate our reduced-form structure in the context of a simple version of this model. Second, we consider an extension of this model that more closely resembles the one in the Mortensen and Pissarides (1994) matching model.

\section{A. Basic Model}

There is a continuum of identical workers with total mass equal to one. Each worker has preferences defined by

$$
\sum_{t=1}^{\infty} \beta^{t}\left(c_{t}-a n_{t}\right),
$$

where $0<\beta<1$ is a discount factor, $c_{t}$ is consumption, and $n_{t}$ is time spent working. Consumption is restricted to be nonnegative, and time spent working is restricted to be either zero or one. The parameter $a$ measures the disutility associated with working and is assumed to be positive.

There is also a continuum of identical agents whom we refer to as entrepreneurs, each with preferences defined by

$$
\text { (4) } \sum_{t=1}^{\infty} \beta^{t} c_{t} \text {, }
$$

where $\beta$ and $c_{t}$ are as above. For reasons that will become clear shortly, we assume that each entrepreneur is endowed with $\bar{c}$ units of the consumption good in every period.

There are two technologies in this economy, one that describes the production of output by a matched worker-entrepreneur pair, and another that describes the process by which workers and entrepreneurs become matched. We begin with the former. A matched pair produces output $s_{t} y$, if it is productive and 0 otherwise. The variable $s_{t}$ is an aggregate 
technology shock assumed for simplicity to follow a symmetric two-state Markov chain in which $\phi\left(=\phi_{11}=\phi_{22}\right)$ is the probability of remaining in the same state for two consecutive periods. We assume that $s_{1}>s_{2}$, and we refer to $s_{1}$ as the good state and $s_{2}$ as the bad state. $^{8}$

In addition to the aggregate shock, each matched pair faces an idiosyncratic shock which determines whether the pair remains productive. The probability of such a realization is the same for all matches currently producing, but realizations are independent across matches. The probability that a match which produced output in period $t-1$ will become unproductive in period $t$ is given by $\lambda_{t}$ and is realized at the beginning of period $t$. The variable $\lambda_{t}$ also follows a two-state Markov chain and is perfectly correlated with the aggregate technology shock. Hence, when $s$ takes on the value $s_{j}, \lambda$ is assumed to take on the value $\lambda_{j}$. We assume that $\lambda_{1}<\lambda_{2}$, so that the probability of a match becoming unproductive is greater during bad times. Once a match becomes unproductive, it remains in this state forever.

The distinguishing feature between an entrepreneur and a worker is that entrepreneurs have the ability to create job vacancies. We assume that this can be done costlessly. To produce output, however, the job vacancy must be matched with a worker, and the process of finding such a match does require time and resources. In particular, it costs an entrepreneur $k$ units of consumption to post a vacancy. ${ }^{9}$ We assume that unmatched workers can search costlessly, whereas matched workers are assumed to be unable to search; i.e., there is no on-the-job search. ${ }^{10}$

We next turn to the matching function. If, in a given period, there are $v$ vacancies posted and $u$ unmatched workers searching, the number of matches formed between entrepreneurs and workers is given by the matching function $m(v, u)$. The probability that a given

\footnotetext{
${ }^{8}$ The variable $s_{t}$ refers to the value of $s$ in period $t$, which may be either $s_{1}$ or $s_{2}$. While this notation is obviously abusive, we think the potential confusion is minimal.

${ }^{9}$ Alternatively, one can assume that there is an initial cost $k_{1}$ to create a vacant position and a cost of $k_{2}$ each period in which it is posted. If, in equilibrium, there are always new vacancies created, then the two specifications have identical implications for employment, job creation, and job destruction if $k=k_{1}+k_{2}$. However, in a calibration exercise the two specfications would presumably suggest different outcomes, since $k$ and $k_{1}$ are presumably the same.

${ }^{10}$ Pissarides (1994) extends the matching model to allow for an on-the-job search.
} 
worker is matched with a vacant job is given by

$$
p=\frac{m(v, u)}{u} .
$$

The probability that a given vacancy is matched with a searching worker is given by

$$
q=\frac{m(v, u)}{v}
$$

We assume that the matching function $m$ is nonnegative, increasing in both arguments, concave, less than the minimum of its arguments, and displays constant returns to scale. Constant returns to scale implies that $p$ and $q$ are functions only of the ratio $v / u$.

Any matches that result from search in period $t$ become productive as of period $t+1$. Hence, the law of motion for $u_{t}$ is given by

$$
u_{t+1}=\lambda_{t+1}\left(1-u_{t}\right)+u_{t}-m\left(v_{t}, u_{t}\right)
$$

Note that a worker who was part of a match that dissolves in the beginning of period $t$ is assumed to search in period $t .^{11}$

The last item that needs to be described is the determination of wages. In this environment, a matched worker-firm pair constitutes a bilateral monopoly. As is standard in this literature, we use a generalized Nash bargaining solution in which the worker's threat point is equal to the value of being unemployed, and the entrepreneur's threat point is the value of an unmatched vacancy (which is zero in equilibrium).

We next define a recursive equilibrium for this economy, but before doing so, we must introduce some notation. The aggregate state variable in each period is given by the pair $(j, u)$, where $j$ indexes the aggregate shock, and $u$ is the mass of workers who are searching. There are three value functions of interest representing the utilities of matched entrepreneurs, matched workers, and unmatched workers, denoted by $J_{j}(u), W_{j}(u)$, and $U_{j}(u)$, respectively. Agents take wages and matching probabilities parametrically, since these values depend on the aggregate state. We let $q_{j}(u)$ and $p_{j}(u)$ be the probabilities that searching entrepreneurs and workers find a match, respectively, and let $w_{j}(u)$ be the wage payment to a matched

\footnotetext{
${ }^{11}$ Note also that we have assumed that a match resulting from search in period $t$ is necessarily productive in period $t+1$. This assumption is not significant quantitatively, but it does simplify the analytics. If newly created jobs were subject to becoming unproductive, then job creation and job destruction in period $t+1$ would be functions both of the search efforts in period $t$ and the shock realization in period $t+1$.
} 
worker when the aggregate state is $(j, u)$. The evolution of the aggregate state is described by the function $T_{j}(u)$, where for each $(j, u)$, this function specifies a distribution over next period's value of the state variable.

A recursive equilibrium is then a list of functions $J_{j}(u), W_{j}(u), U_{j}(u), q_{j}(u), p_{j}(u)$, $w_{j}(u)$, and $T_{j}(u)$ such that

1. (Optimization) Taking the functions $q_{j}, p_{j}$, and $w_{j}$ as given, $J_{j}, W_{j}$, and $U_{j}$ satisfy the appropriate Bellman equations.

2. (Free Entry) $\beta q_{j}(u) E_{j} J_{j^{\prime}}\left(u^{\prime}\right)=k$ for all $(j, u)$, where $\left(j^{\prime}, u^{\prime}\right)$ is next period's value for the aggregate state variable.

3. (Bargaining) $W_{j}(u)-U_{j}(u)=\theta\left[W_{j}(u)+J_{j}(u)-U_{j}(u)\right]$.

4. (Rational Expectations) For each $(j, u)$, decisions generate a distribution over next period's state which is equal to the distribution given by $T_{j}(u)$.

It is standard in the related literature to study equilibria in which wages depend only upon the aggregate technology shock and not on the level of unemployment. ${ }^{12}$ To see why such an equilibrium may exist, assume that $w_{j}$ is the wage rate if the aggregate shock takes on value $j$. In this case, the value to an entrepreneur of a currently productive match when the aggregate technology shock is $j$ satisfies

$$
J_{j}(u)=s_{j} y-w_{j}+\beta \sum_{i=1}^{2} \phi_{j i}\left(1-\lambda_{i}\right) J_{i}\left(u_{i}^{\prime}\right), j=1,2,
$$

where $u_{i}^{\prime}$ is next period's unemployment rate conditional on shock $i$ being realized. Given wages, one can easily solve this set of equations for values of $J_{j}$ that do not depend upon the level of unemployment, since it reduces to a set of two linear equations in two unknowns. This observation, in conjunction with the free-entry condition

$$
k=\beta q_{j} \sum_{i=1}^{2} \phi_{j i} J_{i}
$$

implies that (in equilibrium) the $q_{j}$ do not depend on $u$, and by constant returns to scale of $m$, neither do the $p_{j}$.

\footnotetext{
${ }^{12}$ While it is straightforward to show that such an equilibrium exists, we have not been able to rule out the possibility that equilibria which do not satisfy this property may also exist. We also note that it is easy to show that optimal allocations have the property that $q$ and $p$ do not depend on the level of unemployment.
} 
The two value functions for workers are

$$
W_{j}(u)=w_{j}-a+\beta \sum_{i=1}^{2} \phi_{j i}\left[\left(1-\lambda_{i}\right) W_{i}\left(u_{i}^{\prime}\right)+\lambda_{i} U_{i}\left(u_{i}^{\prime}\right)\right], j=1,2,
$$

for a matched worker and

$$
U_{j}(u)=\beta\left[p_{j} \sum_{i=1}^{2} \phi_{j i} W_{i}\left(u_{i}^{\prime}\right)+\left(1-p_{j}\right) \sum_{i=1}^{2} \phi_{j i} U_{i}\left(u_{i}^{\prime}\right)\right], j=1,2
$$

for an unmatched worker, where we have again used $u_{i}^{\prime}$ to represent next period's unemployment rate conditional upon the realization of the shock being $i$. Since the $p_{j}$ do not depend on $u$, these equations have solutions for $W_{j}$ and $U_{j}$ that also do not depend on $u$.

Finally, note that the above argument is consistent in the sense that if none of the value functions depend on $u$, then condition (3) of equilibrium implies that wages do not depend on $u$. While the argument supplied above implies only that it is logically consistent to look for an equilibrium of this type, it does not guarantee existence of an equilibrium. It is, however, straightforward to show that an equilibrium will exist under relatively mild assumptions.

Although the value functions and parametric functions (i.e., $w, p$, and $q$ ) do not depend on $u$, it does not follow that the level of $u$ in a particular period does not affect outcomes in that period. For example, since $q_{j}$ does not depend on $u$, it follows that the number of vacancies posted is a function of $u$. Additionally, given that $p_{j}$ does not depend on $u$, it follows that holding the value of the aggregate shock constant, the number of workers who find jobs is increasing in the level of unemployment.

Assuming that the aggregate shocks are persistent, i.e., that $\phi=\phi_{11}=\phi_{22}>.5$, it is straightforward to show that $J, W, U, w$, and $p$ are all greater when $j=1$ than when $j=2$, and conversely for $q$. Most of these results should appear intuitive; the only ones on which we remark are the behavior of $q$ and $p$. Note first that constant returns to scale in the matching function, $m$, implies that $q$ and $p$ must move in opposite directions. Second, if the value of a match to an entrepreneur is greater in good times than in bad, it follows from equation (9) that $q$ is necessarily decreasing in $j$ since, in equilibrium, vacancies are posted up to the point that the return to posting a vacancy is driven to zero. Because the value of a match is greater in good times, it must be that the probability that an entrepreneur finds a match is lower. 


\section{B. Reduced-Form Labor Market Dynamics}

One of the attractive features of this model is that a relatively small set of parameters are sufficient to completely characterize its implications for the time series in which we are interested. In particular, it suffices to know the values of the $\lambda_{j}$, the $p_{j}$, and $\phi$. Given an initial unemployment rate and any realization of aggregate shocks, repeated application of equation (7) in conjunction with $m\left(v_{t}, u_{t}\right)=p_{t} u_{t-1}$ allows one to solve for the time series of employment, job creation, and job destruction:

$$
\begin{aligned}
e_{t+1} & =\left(1-\lambda_{t+1}\right) e_{t}+p_{t}\left(1-e_{t}\right) \\
C_{t} & =p_{t-1}\left(1-e_{t-1}\right) \\
D_{t} & =\lambda_{t} e_{t}
\end{aligned}
$$

Of course, the $p_{j}$ 's are themselves functions of all of the model's structural parameters. One way to proceed would be to solve for this mapping and determine whether one can find a reasonable set of structural parameters of the model such that it can account for the facts displayed in Section 2. Here, however, we pursue the alternative strategy of treating the reduced-form parameterization (i.e., $\lambda_{1}, \lambda_{2}, p_{1}, p_{2}$ and $\phi$ ) as the primitive and examine the extent to which this reduced form can account for the cyclical facts documented earlier.

There are three reasons for pursuing this alternative. First, the reduced form is a very parsimonious representation of the model's implications and hence facilitates exposition of the mechanics of the model. Second, studying the reduced form dramatically reduces the dimensionality of the space that one searches over to assess the model's ability to capture a certain set of facts. Third, there are several reasonable extensions to the above model which would yield the same reduced form but change the mapping from structural parameters to the $p_{j}$ 's. Here we briefly mention three. In the first case, assume that there is a choice of effort and/or hours in each productive match. This would require additional functional form assumptions and parameter values to describe preferences over hours and/or work effort and the implications for output of changes along these two margins. However, independently of how these features are introduced, it is relatively straightforward to see that a reduced form identical to that considered above would still result. In the second case, assume that 
workers who are unemployed make a decision about search intensity. This would also require additional functional form assumptions and parameter value assignments, but assuming that the matching function still displays constant returns to scale, the reduced form would remain unchanged. Lastly, one could imagine other ways of resolving the bargaining problem which would leave the reduced form unchanged but alter the structural mapping.

The above discussion also serves to illustrate why we chose to focus only on a subset of the variables for which the model makes predictions. For example, we do not study the model's implications for productivity movements. The reason is that productivity movements are not robust to the kinds of changes discussed in the previous paragraph. Hence, the issue of whether the matching model can account for productivity movements in conjunction with those in employment, job creation, and job destruction would seem to be more an exercise of investigating the role of alternative specifications within this general class of models. We leave this for future work.

Before considering a more general model, we note that it is straightforward to find a specification of this model so as to obtain any reduced form with $p_{1}>p_{2}$. To see this, note that with constant returns to scale, determining the $p_{j}$ 's is equivalent to determining the $q_{j}$ 's. The two zero profit conditions can be rearranged to yield

$$
\begin{aligned}
& \frac{q_{1}}{q_{2}}=\frac{J_{2}}{J_{1}} \\
& \beta q_{1}\left(\phi_{11} J_{1}+\phi_{12} J_{2}\right)=k .
\end{aligned}
$$

If, for example, we set $\theta=0$, then it follows that $w_{1}=w_{2}=a$, and the $J_{j}$ are easily determined by the values of the $y_{j}, \lambda_{j}$, and $\phi_{i j}$. Moreover, any ratio of $\frac{J_{1}}{J_{2}}$ greater than one can be obtained by adjusting the values of the $y_{j}$ 's. Equation (16) can then be used to determine the value of $k$, for example, consistent with the value of $q_{1}$. A related issue of interest is whether any reduced form can be obtained as an efficient equilibrium for some specification of the economy. The parameterization given above would typically result in an equilibrium which is not efficient. If, for example, the matching function is given by $a v^{1-\eta} u^{\eta}$, then equilibrium is efficient if and only if $\theta=\eta$. (See Hosios (1990) for a discussion related to this point.) While we have not established a result connecting our reduced form to structural specifications for which the equilibrium is efficient, we note that the added restriction is not 
obviously an issue, since all that is required is enough freedom to achieve any value for the ratio of $J_{2}$ to $J_{1}$.

\section{Extension of the Basic Model}

In the model described above, aggregate shocks affect both the productivity of a match and the probability that the match is destroyed. One innovation of Mortensen and Pissarides (1994) is to endogenize the job destruction decision. In this subsection, we extend the basic model to incorporate this decision. Productivity of a match is now the sum of two components: an aggregate (or common) component $y$ and an idiosyncratic component denoted by $\epsilon$. Each new match starts with an idiosyncratic productivity equal to $\epsilon_{u}$, which subsequently evolves stochastically. ${ }^{13}$ The stochastic process describing this evolution is the same for all matches, although realizations are independent across matches. For reasons of analytical tractability, it is assumed to take the following special form. In each period, with probability $\gamma$, a given match receives a new value for its idiosyncratic component. If it does receive a new draw, it is a random draw from a distribution with $\operatorname{cdf} F(\epsilon)$, which has support on $\left[\epsilon_{l}, \epsilon_{u}\right]$, where $\epsilon_{l}$ $<\epsilon_{u}$. Note that conditional upon receiving a new draw, the previous value of $\epsilon$ is irrelevant. The process does display positive persistence, since this period's idiosyncratic component is the same as last period's in the absence of a new draw.

The assumption about timing is that at the beginning of a period, each match which is produced in the previous period receives its current realization for the idiosyncratic shock. (All new matches have idiosyncratic component $\epsilon_{u}$.) Subsequently, everyone observes the realization of the aggregate shock, at which point all matched pairs decide whether to continue or separate, and search decisions are made.

Describing an equilibrium is now slightly more complicated. First, relative to the previous model, there is an additional decision of whether to destroy existing matches; i.e., there is no longer an exogenous variable $\lambda$ that describes separations. It is straightforward to show, however, that the optimal destruction decision is characterized by a reservation productivity level, which we denote by $\bar{\epsilon}$. This reservation value is dependent on the aggregate technology

\footnotetext{
${ }^{13}$ What matters for our reduced form is simply that the starting productivity is sufficiently high to warant forming a match for at least one period. Subject to this being true, there is no problem if the stating values for new matches are drawn from a distribution.
} 
shock, and it can be shown that $\bar{\epsilon}_{1}<\bar{\epsilon}_{2}$; i.e., during bad times a higher idiosyncratic component is required to stay in business. Second, the aggregate state variable is now of greater dimensionality. Whereas previously, the aggregate state variable was the aggregate shock and the mass of employed (or equivalently, unemployed) workers, it is now the aggregate shock and the distribution of matches across idiosyncratic productivities. We denote the latter by a measure $\mu$. Note that one can infer the unemployment rate from the measure $\mu$.

However, the stochastic process on idiosyncratic shocks does simplify the model's mechanics. If the aggregate shock assumes value $j$ for two consecutive periods, the fraction of matches that are destroyed is given by $\lambda_{j}=\gamma F\left(\bar{\epsilon}_{j}\right)$, i.e., the fraction of matches which both receive a new draw and obtain a new value of $\epsilon$ that lies below the reservation value. In particular, this value does not depend on the distribution $\mu$. If the aggregate shock goes from the low productivity state to the high productivity state, the fraction of jobs destroyed is still given by $\lambda_{1}$. If, however, the economy moves from the high productivity state to the low productivity state, the fraction of matches destroyed exceeds $\lambda_{2}$, because all matches that did not receive new draws but have an idiosyncratic component $\epsilon$ that satisfies $\bar{\epsilon}_{1}<\epsilon<\bar{\epsilon}_{2}$ will also be destroyed. The mass of these matches is given by $(1-\gamma) \int_{\epsilon_{1}}^{\epsilon_{2}} \mu(\epsilon) d \epsilon$.

It should be clear that the reduced-form dynamics of this model for employment, job creation, and job destruction are identical to those of the basic model discussed earlier, with the exception of those periods in which the economy moves from a good state to a bad state. The extent of this difference depends on the distribution of matches $\mu$ at the time of the change and hence is not constant over time. Note, however, that holding the aggregate shock constant, the measure $\mu$ will converge to some measure $\mu_{j}$ depending on $j$. From a practical perspective, if the aggregate shocks are fairly persistent, then this additional destruction may be reasonably well approximated by the term $\lambda_{0}=(1-\gamma) \int_{\epsilon_{1}}^{\epsilon_{2}} \mu_{1}(\epsilon) d \epsilon$, which is constant over time. With this approximation, the implications of the extended model for employment, job creation, and job destruction are completely specified by the six numbers $\phi, \lambda_{0}, \lambda_{1}, \lambda_{2}, p_{1}$, and $p_{2}$, so that the only difference between this model and the basic model is the additional parameter $\lambda_{0}$. In what follows, we will use this approximation as our reduced form. ${ }^{14}$

\footnotetext{
${ }^{14}$ One way to judge the merits of this approximation is to apply it to the numerical example in MortensenPissarides (1994). When we did this, we found that the summary statistics on which we focus were very
} 


\section{Cyclical Behavior of Creation and Destruction: Analytic Results}

In this section, we explore analytically the model's implications for the response of job creation and job destruction to a change in the aggregate shock. For simplicity, we focus on the reduced form of the basic model, i.e., the case in which $\lambda_{0}=0$, but our results do not depend upon this restriction. Note first that if the aggregate shock takes on the same value repeatedly, the economy converges to a state in which unemployment is constant. In particular, assuming a long sequence of realizations of aggregate shock $j$, the unemployment rate converges to the level

$$
\hat{u}_{j}=\frac{\lambda_{j}}{p_{j}+\lambda_{j}}
$$

from which it follows that $\hat{u}_{1}<\hat{u}_{2}$. We call $\hat{u}_{1}$ and $\hat{u}_{2}$ conditional steady states, to indicate that they are states which reproduce themselves conditional on the realization of the aggregate shock. Moreover, starting from any initial unemployment rate, if the aggregate shock remains unchanged for many periods, unemployment converges monotonically to the level $\hat{u}_{j}$ as long as $p_{j}+\lambda_{j}$ is less than one, a condition which is strongly supported by the data.

Our main interest here is in the cyclical behavior of job creation and job destruction, defined by

$$
\begin{aligned}
& C_{t}=p_{t-1} u_{t-1} \\
& D_{t}=\lambda_{t}\left(1-u_{t}\right) .
\end{aligned}
$$

If unemployment is not changing over time, then job creation must equal job destruction. As a theoretical matter, it is possible for either of the two conditional steady states to have the higher level of job creation and job destruction, since there are offsetting effects (i.e., $p$ and $u$ move in opposite directions across conditional steady states, as do $\lambda$ and $(1-u)$ ). As a practical matter, it is reasonable to assume that the high-employment conditional steady state is associated with lower levels of job creation and job destruction. (This corresponds to the observation in Davis and Haltiwanger (1992) that total job reallocation is countercyclical.)

To make the discussion more concrete, assume that the economy is in the good state and unemployment is $\hat{u}_{1}$ when the economy experiences a shift from the good state to the bad

similar. 
state, where it stays for many periods. Figure 1 shows the response of job creation and job destruction. The increase in $\lambda$ causes job destruction to increase initially, but this is followed by a monotonic decline as employment moves monotonically to its new lower conditional steady state.

Job creation is initially unchanged, since the change in the technology shock does not affect last period's hiring. Subsequently, however, there are offsetting effects on job creation. On the one hand, the probability that an unemployed worker finds a job is lower, tending to make job creation decrease. On the other hand, the level of unemployment is monotonically increasing, tending to make job creation increase. Because job creation and job destruction will eventually be equal (we are assuming no further changes in the aggregate shock), the latter effect must eventually dominate. However, the former effect may dominate early on, as it does in Figure 1, since this is when unemployment is lowest.

Obviously, it is somewhat of an empirical issue as to whether this dynamic response produces a positive or negative correlation between job creation and job destruction. The above analysis predicts that there is at least one period following the shock in which job creation is below average and job destruction is above average, but not necessarily more than one. ${ }^{15}$ The next section is devoted to an examination of the quantitative predictions of the model. It is of interest, however, to provide some intuition for the circumstances under which it is more likely that a negative correlation will obtain.

The previous discussion suggests two mechanisms through which the model may produce a negative value for this correlation. One is relatively frequent changes in the aggregate technology shock, since the initial effect of a switch in the aggregate technology shock is to produce a negative correlation. ${ }^{16}$ The other is slow adjustment of employment to its conditional steady-state value, since the closer employment is to its conditional steady state the more likely it is that job creation and job destruction are in the same position relative to their average values.

\footnotetext{
${ }^{15}$ Caballero and Hammour (1996) note that the importance of this initial period obviously diminishes as the time period is shortened. As our analysis indicates, however, it does not follow that creation and destruction are necessarily positively correlated.

${ }^{16}$ More specifically, changes in the aggregate shock from above average to below average or vice versa are what matter. Hence, there is no strong reason to suspect that having more values for the aggregate shock would improve the model's ability to account for the data.
} 
In the model, it is clear how to bring about more frequent aggregate shocks - this is caused exclusively by a decrease in $\phi$. At the same time, however, it is to be expected that there is a strong tension associated with moving in this direction: in the data, employment is strongly autocorrelated, and increasing the frequency of shocks is expected to decrease the persistence in employment. What affects the rate of convergence to a conditional steady state in the model may be less transparent. We discuss two channels here. The first concerns the average levels about which the economy fluctuates, and the second has to do with the relative importance of shocks to $\lambda$ and $p$.

We begin by rewriting equation (12) as

$$
u_{t+1}-u_{t}=\lambda-(\lambda+p) u_{t}
$$

which can be rearranged to yield

$$
u_{t+1}=u_{t}+(\lambda+p)\left(\hat{u}-u_{t}\right)
$$

where $\hat{u}$ is the conditional steady-state unemployment rate associated with the values of $\lambda$ and $p$. Equation (21) says that the rate at which unemployment converges to its conditional steady state is equal to $\lambda+p$. An implication of this is that lower average values of $\lambda$ and $p$ should lower the correlation between job creation and job destruction. As we shall see empirically, the average value of $p$ is much greater than the average value of $\lambda$, so that the speed of convergence is largely dictated by $p$.

To motivate the second channel, we ask the question: Holding the change in conditional steady-state unemployment constant, does the extent to which the increased unemployment is caused by changes in $p$ versus changes in $\lambda$ matter for the correlation between $C$ and $D$ ? To answer this, recall our earlier discussion of the dynamics following a change in the aggregate shock. The effect which pushes creation in the opposite direction to the change in destruction is due to the decrease in $p$. After the initial period, there are opposing effects at work on job creation. On the one hand, the increased unemployment brought about by the increase in $\lambda$ causes job creation to increase. On the other hand, the decrease in $p$ causes job creation to decrease. This suggests that the greater the change in $p$ relative to $\lambda$, the greater is the likelihood that the second effect dominates, at least for some amount of time. (Recall that the first effect must eventually dominate.) The extent to which this effect is useful, however, 
may be limited by the fact that in the data, job destruction is more volatile than job creation, suggesting that there may be limits on the volatility of $p$ relative to $\lambda$.

\section{Results}

\section{A. Mortensen-Pissarides' Numerical Example}

As mentioned in the introduction, readers familiar with the Mortensen-Pissarides (1994) paper may be under the impression that we are attacking a solved problem, since that paper contains a numerical example with reasonable parameter values that mimics fairly well some business cycle facts for the rates of job creation and job destruction. It turns out, however, that while their example does well along some dimensions, its does not do so well on others. In fact, it is these problems along other dimensions that motivate our analysis. Therefore it seems worthwhile to begin by reporting the larger set of statistics for the Mortensen-Pissarides example. We emphasize that their numerical example does not claim nor even necessarily intend to capture a larger set of cyclical facts than they report in their article. One interpretation of our work is an attempt to extend the success of the Mortensen-Pissarides example to a larger set of cyclical facts.

Table 2 provides the same information for the MP model as Table 1 did for the data. ${ }^{17}$ To obtain these statistics, we simulate the model for 500 periods, discard the first 100 observations, and then log and filter the series consisting of 400 observations. We repeat this procedure 100 times and compute averages for the 100 samples. We throw away the first 100 observations in each run to minimize the potential effect of initial conditions.

\footnotetext{
${ }^{17}$ Note that the statistics reported in Table 2 are not reported in Mortensen and Pissarides' Table II. First, our statistics are shown for the levels of job creation and job destruction, whereas their statistics are shown for the rates. Second, our statistics are shown for data that has been logged and filtered. In the interest of space, we have limited ourselves to the statistics shown. We note however, that the conclusions are not sensitive to whether one focuses on rates rather than levels or on raw data rather than filtered data. However, filtering the data can affect one's perception of along which dimensions the data and model are most at odds.
} 
Table 2

Results for Mortensen and Pissarides' Numerical Example

(filtered data)

\begin{tabular}{|c|c|c|}
\hline \multicolumn{3}{|c|}{ 2a. Standard Deviations and Autocorrelations } \\
\hline & standard deviation & autocorrelation \\
\hline Employment & .017 & .47 \\
\hline Job Creation & .121 & .17 \\
\hline Job Destruction & .147 & -.07 \\
\hline
\end{tabular}

\begin{tabular}{|c|c|c|c|}
\hline \multicolumn{4}{|c|}{ 2b. Contemporaneous Correlations } \\
\hline & Employment & Job Creation & Job Destruction \\
\hline Employment & 1.00 & -.08 & -.81 \\
\hline Job Creation & -.08 & 1.00 & -.43 \\
\hline Job Destruction & -.81 & -.43 & 1.00 \\
\hline
\end{tabular}

\begin{tabular}{|c|c|c|c|c|c|c|c|}
\hline \multicolumn{1}{|c|}{ 2c. Correlations With Employment at Leads and Lags } \\
\hline & $t-3$ & $t-2$ & $t-1$ & $t$ & $t+1$ & $t+2$ & $t+3$ \\
\hline Job Creation & -.21 & -.46 & -.86 & -.08 & .03 & .07 & .10 \\
\hline Job Destruction & .08 & .09 & .11 & -.81 & -.38 & -.17 & -.07 \\
\hline
\end{tabular}

A comparison of Table 2 with Table 1 is informative. First, note that the model does account for some qualitative features found in the data. In terms of relative volatilities, both job creation and job destruction are more volatile than is employment, and job destruction is more volatile than is job creation. In terms of correlations, job destruction is negatively correlated with employment and job creation, whereas job creation displays very little correlation with employment. There are, however, some important quantitative discrepancies. First, the autocorrelations in all three series are far too low relative to the data. Second, creation is too volatile relative to employment and destruction. Third, the contemporaneous correlation between employment and destruction is too negative. We note additionally that creation would appear to be not sufficiently correlated with future employment, and destruction is not sufficiently correlated with lagged employment.

Recall the discussion from the previous section. We argue that one way to obtain a negative correlation between job creation and job destruction is to have frequent shocks, which intuitively should translate into a lower autocorrelation in employment. Although the above simulations do deliver the negative correlation, it seems possible that it is coming at the expense of matching the autocorrelation in employment. 
As we have stressed, this particular numerical example is not constructed in an attempt to reproduce the facts in Section 2, nor is it meant as a calibration exercise. Hence, the above discrepancies do not provide much information on whether some reasonable version of the Mortensen-Pissarides model can account for the larger set of facts. The issue we turn to next is whether one can obtain improvement along the dimensions for which the match is particularly bad without sacrificing the success achieved along other dimensions. Rather than searching over structural specifications of the MP model, we search over specifications of the reduced form outlined in the previous section. As we argue earlier, we think this approach offers three advantages: robustness, transparency, and parsimony.

\section{B. Findings From Reduced-Form Analysis}

In this subsection, we report our findings on the ability of the reduced-form model parameterized by $\phi, \lambda_{0}, \lambda_{1}, \lambda_{2}, p_{1}$, and $p_{2}$ to account for the cyclical facts documented in Section 2. Recall that the reduced-form model is summarized by the following equations:

$$
\begin{aligned}
u_{t+1} & =\lambda_{t+1}\left(1-u_{t}\right)+\left(1-p_{t}\right) u_{t} \\
C_{t} & =p_{t-1} u_{t-1}, D_{t}=\lambda_{t}\left(1-u_{t}\right) \\
p_{t} & =p_{s_{t}}, \lambda_{t}=\lambda_{s_{t}}+\chi\left(s_{t}=2, s_{t-1}=1\right) \lambda_{0},
\end{aligned}
$$

where $s_{t}$ is the aggregate shock in period $t$, and $\chi\left(s_{t}=2, s_{t-1}=1\right)$ is an indicator function which takes on the value 1 if $s_{t}=2$ and $s_{t-1}=1$ and 0 otherwise.

There are six parameters that need to be specified. Looking ahead to our results, we will find it convenient to think in terms of the average values for $p$ and $\lambda$ and the magnitude of fluctuations in each series. This leads us to consider an alternative parameterization in which $\hat{p}$ and $\hat{\lambda}$ are defined as the means for the $p_{j}$ 's and $\lambda_{j}$ 's, respectively, and $\sigma_{p}$ and $\sigma_{\lambda}$ are defined as the percent deviations in $p$ and $\lambda$, respectively, from their average values. The four parameters $p_{j}$ and $\lambda_{j}, j=1,2$ are given by

$$
\begin{aligned}
& p_{1}=\left(1+\sigma_{p}\right) \hat{p}, p_{2}=\hat{p} /\left(1+\sigma_{p}\right) \\
& \lambda_{1}=\hat{\lambda} /\left(1+\sigma_{\lambda}\right), \lambda_{2}=\hat{\lambda}\left(1+\sigma_{\lambda}\right) .
\end{aligned}
$$


The values $\hat{p}$ and $\hat{\lambda}$ can be interpreted as describing long-run or average properties, whereas $\phi, \lambda_{0}, \sigma_{p}$, and $\sigma_{\lambda}$ can be interpreted as describing the cyclical properties. ${ }^{18}$ In particular, it is easy to see that $\hat{p}$ determines the average duration of an unemployment spell (the average duration is equal to the inverse of $\hat{p}$ ), whereas $\hat{\lambda}$ is the average job destruction rate. Recall from our earlier analysis that an economy with $p$ always equal to $\hat{p}$ and $\lambda$ always equal to $\hat{\lambda}$ would have steady-state unemployment given by

$$
\hat{u}=\frac{\hat{\lambda}}{\hat{p}+\hat{\lambda}}
$$

One of our findings is that the extent to which this model can account for the business cycle facts depends critically on the average values about which the economy fluctuates. We emphasize that these average values are simply a device used to organize our findings; in our model, the economy is never in a state in which $p$ equals $\hat{p}$ or $\lambda$ equals $\hat{\lambda}$.

Our analysis proceeds as follows. We choose values for $\hat{p}$ and $\hat{\lambda}$ according to some criterion and then investigate the extent to which the specification can account for the cyclical facts for some choice of $\phi, \lambda_{0}, \sigma_{p}$, and $\sigma_{\lambda}$. There is no presumption that this model can or should account for all the facts; our interest is in assessing the extent to which it can capture a substantial fraction of what we find in the data.

Initially, we adopt a rather weak definition of what constitutes success. We look at four dimensions: variability of employment, autocorrelation of employment, relative variability of job creation and job destruction, and the contemporaneous correlation between job creation and job destruction. Our cutoff for success is that the model simultaneously accounts for at least half of observed employment variability (but no more than 1.2 times the actual variability), predicts an autocorrelation for employment of at least .8, predicts that job destruction is at least as variable as job creation, and predicts a negative contemporaneous correlation between job creation and job destruction. These are very weak conditions-even if they were all to be satisfied, it is not clear that one would necessarily claim to quantitatively account for the business cycle facts. However, our first result will be negative, namely, that for the steady-state specification used in the Mortensen-Pissarides numerical example, there

\footnotetext{
${ }^{18}$ The values $\hat{p}$ and $\hat{\lambda}$ are not true means of the series for $p$ and $\lambda$. They are simply a useful device to organize the parameterization.
} 
is no specification of our reduced form which can simultaneously satisfy these criterion. This negative finding is, of course, strengthened by our use of a very weak criterion.

\section{Results Using MP Steady-State Values}

We begin with a specification in which $\hat{\lambda}$ equals .055 and $\hat{p}$ equals .6. The choice of $\hat{\lambda}$ is motivated by the fact that in the Davis-Haltiwanger-Schuh data, the sample average for the quarterly job destruction rate is 5.5 percent. The choice for $\hat{p}$ implies an average duration of (completed) unemployment spells equal to 1.67 quarters or roughly 21 weeks. In conjunction with the choice of $\hat{\lambda}$, it implies an average unemployment rate of 8.4 percent. These last two figures seem reasonable and basically correspond to the averages used in the simulations of the Mortensen and Pissarides model reported earlier.

We proceed by searching over combinations of $\phi, \lambda_{0}, \sigma_{p}$, and $\sigma_{\lambda}$. For each set of values for these parameters, we simulate the employment dynamics for a run of 500 quarters and compute the sample statistics described above to determine whether the given set of values generates a successful match.

In view of the very weak criterion used to gauge success, our finding is rather striking: we find no parameter values which generate a match. To provide a sense of where the difficulties arise, we present a subset of the relevant summary statistics for one choice of parameters: $\phi=.95$, and $\lambda_{0}=.02$. Although the statistics presented below are not the complete set, we believe they provide the reader with an idea of the tensions present in this specification. 
Table 3

Model Results

(filtered data, $\left.\phi=.95, \lambda_{0}=.02, \hat{p}=.6, \hat{\lambda}=.055\right)$

\begin{tabular}{|c|c|c|c|c||}
\hline \multicolumn{5}{|c|}{ 3a. $\operatorname{corr}\left(C_{t}, D_{t}\right)$} \\
\hline$\sigma_{\lambda} \backslash \sigma_{p}$ & .2 & .4 & .6 & .8 \\
\hline .2 & .11 & -.14 & -.23 & -.25 \\
\hline .4 & .34 & .12 & -.02 & -.08 \\
\hline .6 & .42 & .25 & .13 & .07 \\
\hline .8 & .46 & .33 & .22 & .16 \\
\hline
\end{tabular}

\begin{tabular}{|c|c|c|c|c|}
\hline \multicolumn{5}{|c|}{ 3b. $s d(D) / s d(C)$} \\
\hline$\sigma_{\lambda} \backslash \sigma_{p}$ & .2 & .4 & .6 & .8 \\
\hline .2 & 1.33 & .91 & .66 & .49 \\
\hline .4 & 1.29 & 1.13 & .93 & .72 \\
\hline .6 & 1.26 & 1.19 & 1.04 & .82 \\
\hline .8 & 1.25 & 1.20 & 1.09 & .86 \\
\hline
\end{tabular}

\begin{tabular}{|c|c|c|c|c|c|c|c|c|c|}
\hline \multicolumn{7}{|c|}{ 3c. $s d(E)$} & \multicolumn{5}{|c|}{3 d. corr $\left(E_{t}, E_{t-1}\right)$} \\
\hline$\sigma_{\lambda} \backslash \sigma_{p}$ & .2 & .4 & .6 & .8 \\
\hline .2 & .016 & .022 & .029 & .035 \\
\hline .4 & .023 & .030 & .036 & .043 \\
\hline .6 & .029 & .036 & .043 & .050 \\
\hline .8 & .035 & .043 & .050 & .058 \\
\hline .2 & .86 & .86 & .6 & .83 & .79 \\
\hline .4 & .86 & .86 & .85 & .82 \\
\hline .6 & .85 & .86 & .85 & .83 \\
\hline .8 & .85 & .86 & .85 & .83 \\
\hline
\end{tabular}

\begin{tabular}{|c|c|c|c|c|c|c|}
\hline \multicolumn{7}{|c|}{ 3e. Effects of $\phi$ and $\lambda_{0}$ on Summary Statistics } \\
\hline & \multicolumn{2}{|c|}{$\sigma_{\lambda=.2}, \sigma_{p}=.2, \lambda_{0}=.02$} & \multicolumn{3}{|c|}{$\sigma_{\lambda=.}, \sigma_{p}=.2, \phi=.95$} \\
\hline & $\phi=.9$ & $\phi=.8$ & $\phi=.7$ & $\lambda_{0}=0$ & $\lambda_{0}=.04$ & $\lambda_{0}=.08$ \\
\hline$s d(D) / s d(C)$ & 1.38 & 1.52 & 1.59 & 1.04 & 1.50 & 1.56 \\
\hline $\operatorname{corr}(D, C)$ & .01 & -.21 & -.16 & .08 & .09 & .01 \\
\hline $\operatorname{corr}\left(E_{t-1}, E_{t}\right)$ & .82 & .70 & .66 & .88 & .79 & .62 \\
\hline
\end{tabular}

Not surprisingly, Table 3b indicates that to match $s d(D) / s d(C)$ we basically need to be on or below the diagonal. However, to obtain a negative correlation between $C$ and $D$, Table $3 \mathrm{a}$ indicates that we need to be above the diagonal. This illustrates the tension pointed out in Section 4. Although the correlation between $C$ and $D$ can be decreased by increasing the ratio of $\sigma_{p}$ to $\sigma_{d}$, this improvement along one dimension does not come without negative consequences along other dimensions. There are a few other remarks that are worthy of mention, some of which relate to information not provided above but which are fairly intuitive. The acceptable region in Table $3 \mathrm{~b}$ can be expanded by increasing the size of $\lambda_{0}$. This creates a problem, however, since as $\lambda_{0}$ increases, the persistence in each of the three series decreases, due to the fact that a lot of the variance is attributed to these one-time spikes in destruction. Similarly, as remarked earlier, the acceptable region in Table 3a can be increased by making the shocks more frequent, i.e., decreasing $\phi$. This also has the problem of decreasing the persistence in each of the three series. 
On the basis of our analysis, we conclude that for this steady-state parameterization, the MP model cannot account for the business cycle facts on employment, job creation, and job destruction. This leaves open the question as to whether there are other steadystate parameterizations for which this result does not hold. As discussed in Section 4, there is reason to believe that alternative steady-state specifications may lead to more positive results. We turn to this issue next, postponing until later a discussion of what constitute acceptable steady-state configurations.

\section{Results for Alternative Steady-State Configurations}

As discussed earlier, higher average values of $\lambda+p$ imply faster convergence following shocks. Hence, lower values of this sum will possibly expand the acceptable region in Table 3. We find that a change in the average value of $p$ can bring about a substantial improvement in the degree to which the model's predictions match the facts documented in Section 2. To illustrate this finding, Table 4 presents the results analogous to those in Table 3, but for the case in which $\phi=.85, \lambda_{0}=.02, \hat{p}=.33$, and $\hat{\lambda}=.055$. A few remarks are in order. First, the implied average unemployment rate $\hat{u}$ is equal to .14. Second, a lower value of $\phi$ is used in Table 4 than in Table 3, because the lower value of $\hat{p}$ allows the model to generate sufficient persistence even with a lower value of $\phi$. As seen in Table 4, this specification yields as much autocorrelation in employment as does the previous specification. Lastly, the range of values considered for $\sigma_{p}$ and $\sigma_{\lambda}$ is smaller in Table 4 than it was in Table 3 since, with a smaller value of $\hat{p}$, the model predicts greater volatility in employment holding all else constant. The cases reported in Table 4 generate roughly the same volatility for employment as do the cases reported in Table 3.

Table 4

Model Predictions

(filtered data, $\phi=.85, \lambda_{0}=.02, \hat{p}=.33, \hat{\lambda}=.055$ ) 


\begin{tabular}{|c|c|c|c|c||c|c|c|c|c|}
\hline \multicolumn{5}{|c|}{ 4a. $\operatorname{corr}\left(C_{t}, D_{t}\right)$} & \multicolumn{5}{|c|}{ 4b. $s d(D) / s d(C)$} \\
\hline$\sigma_{\lambda} \backslash \sigma_{p}$ & .10 & .15 & .20 & .25 \\
\hline .10 & -.24 & -.29 & -.30 & -.30 \\
\hline .15 & -.19 & -.29 & -.33 & -.36 \\
\hline .20 & -.12 & -.24 & -.32 & -.36 \\
\hline .25 & -.06 & -.19 & -.28 & -.34 \\
\hline .10 & 2.08 & 1.52 & 1.15 & .93 \\
\hline .15 & 2.08 & 1.70 & 1.36 & 1.12 \\
\hline .20 & 2.04 & 1.80 & 1.52 & 1.29 \\
\hline .25 & 1.98 & 1.84 & 1.62 & 1.42 \\
\hline
\end{tabular}

\begin{tabular}{|c|c|c|c|c||c|c|c|c|c|}
\hline \multicolumn{7}{|c|}{$4 \mathrm{c} . s d(E)$} & \multicolumn{5}{|c|}{ 4d. corr $\left(E_{t}, E_{t-1}\right)$} \\
\hline$\sigma_{\lambda} \backslash \sigma_{p}$ & .10 & .15 & .20 & .25 \\
\hline .10 & .0147 & .0173 & .0200 & .0225 \\
\hline .15 & .0178 & .0205 & .0231 & .0257 \\
\hline .20 & .0208 & .0235 & .0262 & .0287 \\
\hline .25 & .0238 & .0265 & .0291 & .0317 \\
\hline .10 & .10 & .15 & .20 & .25 \\
\hline .15 & .84 & .85 & .86 & .86 \\
\hline .20 & .84 & .85 & .86 & .86 \\
\hline .25 & .84 & .85 & .86 & .86 \\
\hline
\end{tabular}

Although the basic pattern is not much different than in Table 3, a significant difference is that the acceptable regions are now much larger, and in particular, there are settings which satisfy all of the (weak) criteria imposed earlier. To provide more detail for a particular example, we display the facts corresponding to Table 1 for the case with $\sigma_{p}=.25$ and $\sigma_{\lambda}=.25$. 
Table 5

Model Predictions

(filtered data, $\phi=.85, \lambda_{0}=.02, \hat{p}=.33, \hat{\lambda}=.055, \sigma_{p}=.25, \sigma_{\lambda}=.25$ )

\begin{tabular}{|c|c|c|}
\hline \multicolumn{3}{|c|}{ 5a. Standard Deviations and Autocorrelations } \\
\hline & standard deviation & autocorrelation \\
\hline Employment & .032 & .86 \\
\hline Job Creation & .137 & .58 \\
\hline Job Destruction & .194 & .36 \\
\hline
\end{tabular}

\begin{tabular}{|c|c|c|c|}
\hline \multicolumn{4}{|c|}{ 5b. Contemporaneous Correlations } \\
\hline & Employment & Job Creation & Job Destruction \\
\hline Employment & 1.00 & -.14 & -.48 \\
\hline Job Creation & -.14 & 1.00 & -.34 \\
\hline Job Destruction & -.48 & -.34 & 1.00 \\
\hline
\end{tabular}

\begin{tabular}{|c|c|c|c|c|c|c|c|}
\hline \multicolumn{6}{|c|}{ 5c. Correlations With Employment at Leads and Lags } \\
\hline & $t-3$ & $t-2$ & $t-1$ & $t$ & $t+1$ & $t+2$ & $t+3$ \\
\hline Job Creation & -.81 & -.83 & -.53 & -.14 & .03 & .07 & .29 \\
\hline Job Destruction & .30 & .19 & -.02 & -.48 & -.71 & -.69 & -.52 \\
\hline
\end{tabular}

While a comparison of Tables 5 and 2 with Table 1 reveals substantial improvement along several dimensions, it is still the case that this particular example misses along some dimensions. In particular, several of the correlations of job creation and job destruction with leads and lags of employment seem too small in absolute value, and the autocorrelation in destruction seems a bit low. Further reduction in the average value of $p$ brings additional improvement, however. The next two tables repeat the above exercise with $\hat{p}=.25$. This implies an average unemployment rate of roughly .18. 
Table 6

Model Predictions

(filtered data, $\left.\phi=.80, \lambda_{0}=.01, \hat{p}=.25, \hat{\lambda}=.055\right)$

\begin{tabular}{|c|c|c|c|c|c|c|c|c|c|}
\hline \multicolumn{5}{|c|}{ 6a. $\operatorname{corr}\left(C_{t}, D_{t}\right)$} & \multicolumn{5}{|c|}{ 6b. $s d(D) / s d(C)$} \\
\hline$\overline{\sigma_{\lambda} \backslash \sigma_{p}}$ & .10 & .15 & .20 & .25 & $\lambda \backslash \sigma_{p}$ & .10 & .15 & .20 & .25 \\
\hline .10 & -.36 & -.34 & -.33 & -.33 & .10 & 1.64 & 1.10 & .83 & .67 \\
\hline .15 & -.40 & -.41 & -.40 & -.40 & .15 & 2.03 & 1.42 & 1.09 & .88 \\
\hline .20 & -.38 & -.43 & -.44 & -.44 & 20 & 2.30 & 1.71 & 1.33 & 1.09 \\
\hline .25 & -.35 & -.42 & -.44 & -.45 & .25 & 2.45 & 1.94 & 1.55 & 1.28 \\
\hline
\end{tabular}

\begin{tabular}{|c|c|c|c|c|c|c|c|c|c|}
\hline \multicolumn{5}{|c|}{ 6c. $s d(E)$} & \multicolumn{5}{|c|}{ 6d. $\operatorname{corr}\left(E_{t}, E_{t-1}\right)$} \\
\hline$\sigma_{\lambda} \backslash \sigma_{p}$ & 10 & 15 & 20 & .25 & $\sigma_{p}$ & .10 & .15 & .20 & .20 \\
\hline .10 & .0140 & 170 & 201 & 2230 & .10 & .83 & .85 & .85 & \\
\hline 15 & & & & & .15 & .83 & .85 & .85 & .85 \\
\hline .20 & & . & 5 & .0 & .20 & .83 & .84 & .85 & .85 \\
\hline .25 & .0236 & .0266 & .0296 & .0326 & .25 & .83 & .84 & .85 & .85 \\
\hline
\end{tabular}

Table 7

Model Predictions

( filtered data, $\phi=.80, \lambda_{0}=.01, \hat{p}=.25, \hat{\lambda}=.055, \sigma_{p}=.20, \sigma_{\lambda}=.25$ )

\begin{tabular}{|c|c|c|}
\hline \multicolumn{3}{|c|}{ 7a. Standard Deviations and Autocorrelations } \\
\hline & standard deviation & autocorrelation \\
\hline Employment & .030 & .85 \\
\hline Job Creation & .128 & .46 \\
\hline Job Destruction & .198 & .33 \\
\hline
\end{tabular}

\begin{tabular}{|c|c|c|c|}
\hline \multicolumn{4}{|c|}{ 7b. Contemporaneous Correlations } \\
\hline & Employment & Job Creation & Job Destruction \\
\hline Employment & 1.00 & .04 & -.37 \\
\hline Job Creation & .04 & 1.00 & -.44 \\
\hline Job Destruction & -.37 & -.44 & 1.00 \\
\hline
\end{tabular}

\begin{tabular}{|c|c|c|c|c|c|c|c|}
\hline \multicolumn{6}{|c|}{ 7c. Correlations With Employment at Leads and Lags } \\
\hline & $t-3$ & $t-2$ & $t-1$ & $t$ & $t+1$ & $t+2$ & $t+3$ \\
\hline Job Creation & -.74 & -.77 & -.38 & .04 & .24 & .28 & .25 \\
\hline Job Destruction & .33 & .32 & .13 & -.37 & -.66 & -.62 & -.42 \\
\hline
\end{tabular}

Based on a comparison of Table 7 with Table 1, our conclusion is that this specification does account for many of the facts presented in Table 1. Moreover, there seems to be an 
improvement along several dimensions relative to Table 5, with no significant worsening along any other dimension.

In all of the parameterizations analyzed thus far, we have set $\hat{\lambda}=.055$, which is the average quarterly job destruction rate in the data. For reasons we discuss in the next section, this may be viewed as an upper bound for the job destruction rate in the model. To investigate the significance of this choice, we have analyzed our reduced-form model using other values of $\hat{\lambda}$, ranging from .02 to .055. Our findings were very similar, so we do not report the results in any detail. One statistic which is affected by decreasing $\hat{\lambda}$ is the magnitude of employment fluctuations. This is not surprising, since a decrease in $\hat{\lambda}$ holding the percent deviations in job destruction constant will obviously yield smaller percent fluctuations in employment.

We close this section with one final comment related to the difference between the first model described in Section 3 and the Mortensen-Pissarides model, in which job destruction is determined endogenously. An important result from the Mortensen-Pissarides analysis is that once job destruction is endogenized, theory predicts an additional effect, namely, the asymmetry in the job destruction rate induced by negative aggregate shocks. Although our analysis does not permit us to make definitive statements on the issue, our results do suggest that the ability of the model to match the business cycle facts is enhanced by having $\lambda_{0}$ be positive.

\section{Discussion}

The key finding from the previous section is that the model can account for the business cycle facts reasonably well if $\hat{p}$, the average unemployment hazard, is around .33 or lower. A value of $\hat{p}$ this low, however, implies unemployment durations of roughly 39 weeks. According to data published by the Bureau of Labor Statistics, the average duration of unemployment spells in manufacturing for the period 1972-1988 is around 20 weeks. This might suggest that our main finding is negative: for reasonable parameter values, our reduced-form MortensenPissarides model cannot match the business cycle facts in Section 2.

Here we argue the opposite. There are two important issues to consider. ${ }^{19}$ The first is

\footnotetext{
${ }^{19} \mathrm{~A}$ third issue is that whereas the model is a general equilibrium model, we are using it to match data from a single sector. While we view this is a caveat, we do not pursue its potential significance here.
} 
that some care must be taken when using data from the world in which there are three labor market states (i.e., employed, unemployed, and not in the labor force) to calibrate a model in which there are only two states (i.e., employed and unemployed). There would be no issue if transitions between nonparticipation and the other two states were rare, but the data reveal that this is not the case. For example, Blanchard and Diamond (1990) report that the flow of workers from out of the labor force into employment is roughly the same as the flow of workers from unemployment into employment. They also report that the number of workers categorized as out of the labor force but who want a job is roughly equal in magnitude to the number of people in the unemployed state.

These last two facts suggest that it is reasonable to consider some individuals from the out-of-the-labor-market state as individuals who are possibly searching for employment at a low level of intensity. This is significant for the calibration of the steady state of a matching model in which searching workers are assumed to be identical, since the representative searching worker in the model must represent both those unemployed workers who are searching relatively intensely as well as those nonparticipating workers who may be searching less intensely. The key for our calibration exercise is that this interpretation suggests a higher ratio of individuals searching in the steady state relative to those who are employed and hence holding the average value of $\lambda$ constant yields a lower probability of moving from nonemployment to employment. In fact, if one follows Blanchard and Diamond (1989) and counts all nonparticipating individuals who say they want a job as searchers, then in the model's steady state, the fraction of people searching should be roughly twice that of the measured unemployment rate. Taking the reported average unemployment rate in manufacturing of 8.5 percent at face value, this suggests that the specification in Tables 5 and 7 is preferable to that in Table 2.

To pursue this issue further, it is instructive to examine some relationships which must hold in steady state. The steady state of the model is characterized by three numbers: the rate at which employed workers leave employment $(\lambda)$, the rate at which nonemployed workers find employment $(p)$, and the fraction of workers that are employed $(1-u)$. It is important to note, however, that only two of these values are independent, since they are linked by the relationship $u=\lambda /(p+\lambda)$. Taking $\lambda$ as given, therefore, there is a one-to-one mapping 
between choices of $u$ and choices of $p$. Table 8 indicates several possible combinations for steady-state values of $u$ and $p$ for two values of $\lambda, .055$ and $.030 .^{20}$

\footnotetext{
${ }^{20}$ We consider valuess of $\lambda$ less than .055 , since one may argue that the figure of .055 is upward biased for our purposes by the inclusion of some temporary layoffs. Some evidence on this is provided later in the paper.
} 
Table 8

SS $u-p$ Combinations

$\lambda=.055$

\begin{tabular}{|c|c|c|c|c|c|c|c|}
\hline$p$ & .2 & .3 & .4 & .5 & .6 & .7 & .8 \\
\hline$u$ & .22 & .15 & .12 & .10 & .08 & .07 & .06 \\
\hline \multicolumn{8}{|c|}{$\lambda=.030$} \\
\hline$p$ & .2 & .3 & .4 & .5 & .6 & .7 & .8 \\
\hline$u$ & .13 & .09 & .07 & .06 & .05 & .04 & .04 \\
\hline
\end{tabular}

As Table 8 makes clear, one cannot simultaneously have the fraction of employed workers equal to .85 and an unemployment hazard of .6. If one takes the stand that the size of the searching population is 15 percent or higher, a value of $p$ less than .3 is required, even with $\lambda$ set to .055 .

An important qualification should be noted. The model studied here is not intended to capture all of the labor market flows in the real world. In particular, the nature of worker-firm separations in the model is such that the employment position ceases to exist; i.e., it is not filled by a new worker. Hence, it seems natural to interpret the model as abstracting from both temporary layoffs and quits. This is important for two reasons. First, it suggests that the relevant unemployment rate is probably smaller than suggested above. However, since published data on unemployment rates by reason for unemployment indicate that persons on temporary layoff or who left their previous job account for roughly 1.5 percentage points of economywide unemployment, this factor is probably not very significant. Second, unemployment durations are much lower on average for these two groups than they are for other groups in the population, hence, further suggesting that the relevant duration of unemployment is higher than published sources indicate.

The above argument has implicitly treated $p$ as a residual to be determined as the value consistent with specified values of $u$ and $\lambda$. The spirit of the argument, however, is intimately related to a literature that studies unemployment durations directly and argues that measured unemployment spells are significantly downwardly biased because of reporting errors induced by the presence of the out-of-the-labor-force state. (See Clark and Summers (1979) for a discussion of this phenomenon.) The basic issue is that measured unemployment durations do not measure the expected time between employment spells, but rather the expected time 
before leaving the unemployment state to either employment or out of the labor force. In our model, on the other hand, $p$ is probably best interpreted as reflecting the (inverse) of the duration of a nonemployment spell rather than of an unemployment spell. This reasoning also suggests, therefore, that choosing a value for $p$ based on matching reported unemployment durations is not necessarily a good strategy for assessing the model's implications.

The next issue we take up in this section is to pursue the distinction between temporary and permanent separations somewhat further. As already mentioned, the model studied in this paper assumes that all separations are permanent, in the sense that all additions to employment result from a process in which all searching workers have the same probability of being matched with a given vacancy. In reality, some fraction of employment additions are accounted for by workers who have been on temporary layoff and are being recalled to their prior positions. If the business cycle facts presented in Section 2 are dominated by a process of temporary layoffs and recalls, then our modelling strategy reflects a very poor choice.

Unfortunately, the job creation and job destruction data cannot be decomposed into permanent and temporary components, since they cannot tell if a job added to payroll today corresponds to a given worker who was previously on payroll. However, one way to gauge the importance of temporary separations is to consider job creation and job destruction rates for longer horizons than one quarter. This method has been used by Davis and Haltiwanger (1992) and Davis, Haltiwanger, and Schuh (1996). They conclude that temporary separations do not account for the bulk of job reallocation measured with this data.

The procedure used to reach this conclusion is the following. Consider a given establishment for which the number of payroll positions declines between two consecutive interview dates. These deleted positions show up as job destruction according to our definitions. One can check, however, whether the number of payroll positions increases at subsequent interview dates. By checking this at various horizons, one may attempt to exclude those cases of payroll deletions which are reversed soon thereafter. In particular, there may be some presumption that if a given establishment destroys positions in one period and then creates positions in the next period, this may reflect temporary layoffs and recalls. Of course, it may not, but this seems a useful way to bound how much of the activity may be due to temporary layoffs. 
This leads us to examine the properties of job creation and job destruction that result from requiring that the deletions or additions persist for some specified horizon. We have constructed these series using horizons of zero, one, two, four and eight quarters. Zero corresponds to the measures used in Section 2. Table 9 displays summary statistics for each of the series on job creation and job destruction that result. These data have not been seasonally adjusted. 
Table 9

Summary Statistics for Creation and Destruction at Various Horizons 1972:2-1988:4

(data are filtered but not seasonally adjusted)

\begin{tabular}{|c|c|c|c|c|c|c|}
\hline & $s d(D) / s d(C)$ & $\operatorname{corr}\left(C_{t}, D_{t}\right)$ & $\operatorname{corr}\left(C_{t}, C_{t-1}\right)$ & $\operatorname{corr}\left(D_{t}, D_{t-1}\right)$ & mean $(C R)$ & mean $(D R)$ \\
\hline 0 & 1.76 & -.61 & .30 & .45 & .053 & .056 \\
\hline 1 & 1.86 & -.21 & .45 & .38 & .039 & .043 \\
\hline 2 & 1.50 & -.18 & .51 & .42 & .031 & .036 \\
\hline 4 & 1.40 & -.27 & .65 & .48 & .022 & .028 \\
\hline 8 & 1.30 & -.25 & .68 & .45 & .018 & .024 \\
\hline
\end{tabular}

Although the table shows data for several horizons, from the perspective of temporary layoffs, it would seem that the most relevant horizon is one quarter, so we focus our discussion accordingly on the first two rows of the table. As the table indicates, the mean of job creation and job destruction decrease by about 25 percent in this case, supporting the earlier claim that the bulk of the activity corresponds to permanent separations. It is also instructive to examine how the stylized facts change if one looks at these alternative series for creation and destruction. The first four columns of the table show that the stylized facts do not change very much qualitatively, but that there are some differences quantitatively. For example, the correlation between job creation and job destruction is somewhat lower in absolute value, and the autocorrelation of job destruction is lower.

We close this section with a brief discussion of some related papers. There are two recent papers, Andolfatto (1996) and Merz (1996), that imbed matching models into otherwise standard real business cycle models and explore the business cycle implications quantitatively. Andolfatto shows that his model performs about the same as a standard real business cycle model on the dimensions commonly addressed and that it also matches on some dimensions such as the unemployment rate-vacancy rate correlation from which the standard model abstracts. However, although he does not explore the implications of his model for job creation and job destruction, it is clear that his model does not match some of the key empirical regularities. For example, in his model, the job destruction rate is constant, implying that employment and job destruction would have the same volatility in percentage terms.

Merz, however, specifically examines the flows into and out of unemployment and finds that her model successfully accounts for the facts. Moreover, in sharp contrast to our 
findings, this happens when the average unemployment duration is set to 12 weeks. The apparent discrepancy between the two papers is resolved by noting that they study different objects. Merz's empirical work studies economywide flows into and out of unemployment, whereas our empirical work studies job creation and job destruction flows in manufacturing. In both theoretical models, job creation is identical to the outflow from unemployment, and job destruction is identical to the inflow to unemployment. Hence, since Merz finds a positive correlation between the inflow and outflow, she obviously does not account for the negative correlation between job creation and job destruction. Likewise, since our reduced-form model accounts for the negative correlation between job creation and job destruction, it does not account for the positive correlation between the flows into and out of unemployment. However, in the actual data, there is not such a close association between the various measures, which explains why it is possible that job creation and job destruction are negatively correlated, whereas the flows into and out of unemployment are positively correlated. ${ }^{21}$

To understand the discrepancy in the real data, note that Merz measures the monthly flow into unemployment as a constant times the number of individuals unemployed for less than five weeks. There are several reasons why this may not correspond to job destruction. First, if an individual enters unemployment from out of the labor force, then there is an inflow into unemployment, but no job has been destroyed. Similarly, if an individual is laid off and leaves the labor force, then there is no flow into unemployment, but there has been a job destroyed. Or, if one individual quits a job and becomes unemployed and the firm hires a replacement, there is again a discrepancy. The bottom line here is that Merz's empirical work focuses on series that are potentially quite different than the job creation and job destruction series. A relevant question is for which of the two data sets is the model most appropriate? In our view, given that both models abstract from quits and transitions between unemployed and out of the labor force, it is best to focus on the model's implications for job creation and job destruction. At a minimum, the discussion suggests that it may be worthwhile to incorporate these other features into the model.

\footnotetext{
${ }^{21}$ Given the differences in time periods and coverage for the two empirical analyses, there are other explanations for the two findings. However, work with manufacturing turnover data for a longer time period suggests that the time horizon is not the determining factor.
} 
Lastly, one feature of the data that we have not discussed is the presence of countercyclical loops in the dynamics of unemployment and job vacancies. Pissarides (1987) discusses this feature and shows essentially that the model of this paper does not produce this feature of the data. He also suggests one possible remedy which effectively introduces some rigidity in the response of wages to temporary shocks. We leave an integration of this element into the analysis for future work.

\section{Conclusion}

The objective of this paper has been to determine to what extent the MortensenPissarides matching model can account for the business cycle facts on employment, job creation, and job destruction. A novel feature of our analysis has been its focus on the reduced-form implications of the model rather than on the structural specification of the model, since we believe that this facilitates an understanding of the model's mechanics and provides a more robust assessment of the model's empirical implications. Our main finding is that the reduced-form structure implied by the model can account for most of the features found in the data, although this requires that average unemployment durations in the model be substantially larger than those reported in the data. While we have argued that these unemployment durations are not implausible, our argument also suggests that it is important to extend the model in order to better gauge its ability to account for the patterns in the data. In particular, incorporating heterogeneity in search intensity across workers at a point in time as well as allowing for quits and temporary separations seem to be important avenues to pursue. It is also of interest to examine what specifications of structural models give rise to the reduced forms that seem to account for the data, since Caballero and Hammour (1996) argue analytically in a similar but different model that departures from efficiency may be key to accounting for the empirical regularities in job creation and job destruction. 


\section{References}

Andolfatto, D., "Business Cycles and Labor-Market Search," American Economic Review 86, 1996, 112-132.

Bentolila, S., and G. Bertola, "Firing Costs and Labour Demand: How Bad is Eurosclerosis?" Review of Economic Studies 57, 1990, 381-402.

Bertola, G., and A. Ichino, "Wage Inequality and Regional Unemployment: United States vs. Europe," NBER Macroeconomic Annual, 1995, 13-54.

Bertola, G., and R. Rogerson, "Institutions and Labor Reallocation," forthcoming, European Economic Review, 1997.

Blanchard, O., and P. Diamond, "The Beveridge Curve," Brookings Papers on Economic Activity, 1989, 1-76.

, "The Cyclical Behavior of the Gross Flows of U.S. Workers," Brookings Papers on Economic Activity, 1990, 85-143.

Caballero, R., and M. Hammour, "On the Timing and Efficiency of Creative Destruction," Quarterly Journal of Economics 111, 1996, 805-852.

Clark, K., and L. Summers, "Labor Market Dynamics and Unemployment: A Reconsideration," Brookings Papers on Economic Activity, 1979, 13-72.

Cooley, T., Frontiers of Business Cycle Research, Princeton: Princeton University Press, 1995.

Davis, S., and J. Haltiwanger, "Gross Job Creation, Gross Job Destruction and Employment Reallocation," Quarterly Journal of Economics 107, 1992, 819-863.

Davis, S., J. Haltiwanger, and S. Schuh, Job Creation and Destruction, Cambridge, Mass.: MIT Press, 1996.

Dunne, T., M. Roberts and L. Samuelson, "Plant Turnover and Gross Employment Flows in the U.S. Manufacturing Sector," Journal of Labor Economics 7, 1989, 48-71.

Foote, C., "Trend Employment Growth and the Bunching of Job Creation and Destruction," mimeo, University of Michigan, 1996.

Greenwood, J., G. MacDonald, and G. Zhang, "The Cyclical Behaviour of Job Creation and Job Destruction: A Sectoral Model," Economic Theory 7, 1995, 95-112. 
Hopenhayn, H., and R. Rogerson, "Job Turnover and Policy Evaluation: A General Equilibrium Analysis," Journal of Political Economy 101, 1993, 915-938.

Hosios, A., "On the Efficiency of Matching and Related Models of Search and Unemployment," Review of Economic Studies 57, 1990, 279-298.

Merz, M., "Heterogeneous Job Matches and the Cyclical Behaviour of Labor Turnover," mimeo, Rice University, 1996.

Millard, S., and D. Mortensen, "The Unemployment and Welfare Effects of Labor Market Policy," mimeo, Northwestern University, 1995.

Mortensen, D., and C. Pissarides, "Job Creation and Job Destruction in the Theory of Unemployment," Review of Economic Studies 61, 1994, 397-415.

Pissarides, C., "Search, Wage Bargains and Cycle," Review of Economic Studies 54, 1987, 473-483.

, Equilibrium Unemployment Theory, Cambridge, Mass., and Oxford: Blackwell, 1990.

, "Search Unemployment With On the Job Search," Review of Economic Studies 61, 1994, 457-475. 
Figure 1

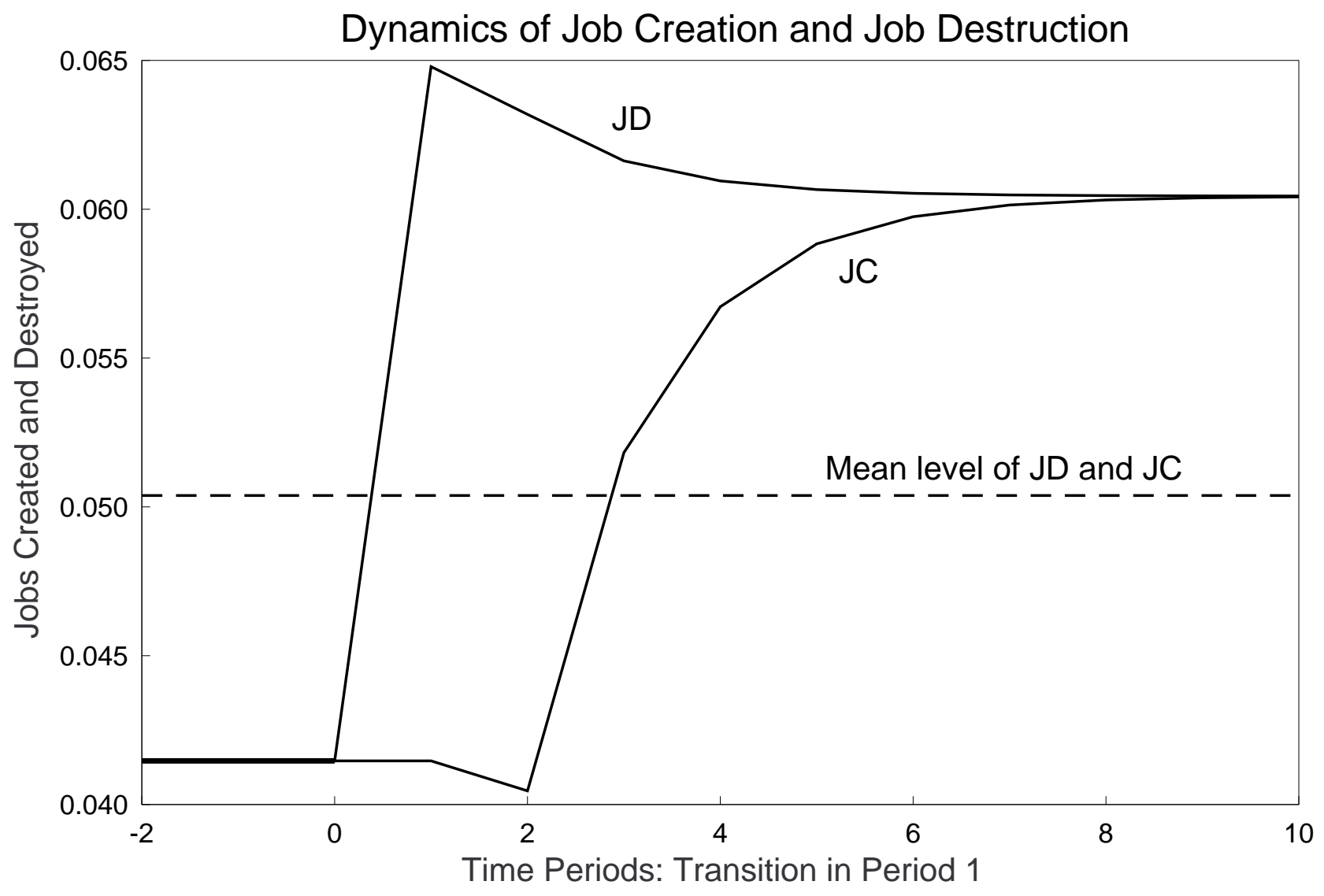

